\title{
Sistem Pendukung Keputusan Pemilihan Kain Terbaik Di Toko Crown Textile \& Tailor Dengan Metode Simple Additive Weighting (SAW)
}

\author{
Sungguh Zebua ${ }^{1 *}$, R. Mahdalena Simanjorang ${ }^{2}$ \\ ${ }^{1,2}$ STMIK Pelita Nusantara \\ Jl. Iskandar Muda No. 1 Medan 20154 \\ Corresponding author's e-mail: sungguhzebua123@gmail.com
}

\begin{abstract}
Abstrak - Bisnis retail terus berkembang pesat seiring dengan berkembangnya ilmu pengetahuan dan teknologi di era globalisasi namun pembelian kain masih dilakukan secara manual dan belum terkomputerisasi seperti dalam memlilih kain hanya melihat bentuk warna serta label harganya saja, jika cocok dan suka langsung diambil tanpa berpikir jenis kain apa yang digunakan untuk pakaian tersebut, ketika sudah dijadikan pakaian atau baju, tidak sesuai dengan kriteria-kriteria yang diinginkan oleh konsumen dan banyak pakaian yang sudah jadi dikembalikan lagi karena warnanya menjadi kusam atau luntur, dan tidak sesuai dengan motif yang diinginkan. Permasalahan pada penelitian ini yaitu menentukan pemilihan kain terbaik menggunakan SPK dengan metode Simple Additive Weighting (SAW) dalam pemilihan kain terbaik di Crown Textile \& Tailor dibangun menggunakan pemograman Php MyAdamin. Metode sistem pendukung keputusan digunakan Simple Additive Weighting (SAW), karena dapat menentukan nilai bobot untuk setiap atribut, melalui proses perankingan menyeleksi alternatif terbaik dari sejumlah data alternatif, diperoleh hasil Kain Viscose Rayon bernilai 0.933, (Ranking 1), Kain Lace Brukat bernilai 0,9 (Ranking 2), Kain Katun Toyobo bernilai 0.716 (Ranking 3), Kain Katun Jepang bernilai 0.700 (Ranking 4).
\end{abstract}

Kata kunci- Data Kain, Kriteria Terbaik, Ranking, SPK, Metode SAW

Abstract - The retail business continues to grow rapidly along with the development of science and technology in the era of globalization, but the purchase of fabric is still done manually and not computerized, such as in choosing fabrics, only looking at the shape of the color and the price tag, if it is suitable and likes it is taken immediately without thinking what type of fabric to use. used for these clothes, when they have been made into clothes or clothes, do not match the criteria desired by consumers and many ready-made clothes are returned because the color becomes dull or faded, and does not match the desired motif. The problem in this study is to determine the selection of the best fabric using SPK with the Simple Additive Weighting (SAW) method in selecting the best fabric at Crown Textile \& Tailor built using PHP MyAdamin programming. The decision support system method used is Simple Additive Weighting (SAW), because it can determine the weight value for each attribute, through a ranking process selecting the best alternative from a number of alternative data, the results obtained are Viscose Rayon Fabrics worth 0.933, (Rank 1), Brukat Lace Fabrics are worth 0.9 (Rank 2), Toyobo Cotton Fabric is worth 0.716 (Rank 3), Japanese Cotton Fabric is worth 0.700 (Rank 4).

Keywords - Fabric Data, Best Criteria, Ranking, SPK, SAW Method

\section{Pendahuluan}

Tekstil memiliki peran yang sangat penting dalam kehidupan manusia. Tekstil adalah suatu bahan yang berasal dari serat dan diolah menjadi benang atau kain sebagai bahan untuk pembuatan busana atau berbagai produk kerajinan lainnya. Kebutuhan akan barang tekstil yang bermutu tinggi membuat perusahaanperusahaan tekstil berusaha untuk membuat produk tekstil dengan kualitas terbaik agar dapat bersaing dipasaran. Perusahaan tekstil memproduksi berbagai macam jenis tekstil yang disesuaikan dengan kebutuhan para konsumen. Produk tekstil yang bermutu baik adalah produk tekstil yang telah memenuhi standar yang ditetapkan oleh Standar Nasional Indonesia (SNI). Crown Textile and Tailor merupakan toko textile terbesar di kota Medan, Crown Textile and Tailor menawarkan berbagai jenis pilihan kain kualitas tinggi dengan harga yang rendah mulai dari eceran sampai grosiran.

Adapun permasalahan yang terjadi dalam pemilihan kain masih dilakukan secara manual dan belum terkomputerisasi seperti dalam memlilih kain hanya melihat bentuk warna serta label harganya saja, jika cocok dan suka langsung diambil tanpa berpikir jenis kain apa yang digunakan untuk pakaian tersebut, ketika sudah dijadikan pakaian atau baju, tidak sesuai dengan kriteria-kriteria yang diinginkan oleh konsumen dan banyak pakaian yang sudah jadi dikembalikan lagi karena warnanya menjadi kusam atau luntur, dan tidak sesuai dengan motif yang diinginkan. Banyak jenis-jenis kain yang bisa dijadikan pakaian atau baju jadi. Namun, tidak semua orang memahami tentang jenis-jenis kain, sehingga dibutuhkan sistem yang dapat membantu 
konsumen dalam melakukan pemilihan kain yaitu dengan sistem pendukung keputusan [1][2].

Sistem Pendukung Keputusan adalah sebuah sistem berbasis komputer dengan antarmuka antara mesin/komputer dan pengguna. Sistem Pendukung Keputusan ditujukan untuk membantu pembuat keputusan dalam menyelesaikan suatu masalah dalam berbagai level manajemen dan bukan untuk mengganti posisi manusia sebagai pembuat keputusan [3]. SPK mampu memberi alternatif solusi bagi masalah semi/tidak terstruktur baik bagi perseorangan atau kelompok dan dalam berbagai macam proses dan gaya pengambilan keputusan [4]. SPK menggunakan data, basis data dan analisa model-model keputusan, ada beberapa metode dalam sistem pendukung keputusan yaitu Analytical Hierarchy Process (AHP), Simple Additive Weighting (SAW), Weighted Product (WP), metode profile matching dan lain-lain [5]. Metode yang digunakan dalam sistem pendukung keputusan ini adalah Metode Simple Additive Weighting (SAW), karena dapat menentukan nilai bobot untuk setiap atribut, kemudian dilanjutkan dengan proses perankingan yang akan menyeleksi alternatif terbaik dari sejumlah alternatif, dalam hal ini alternatif yang dimaksud adalah yang berhak diterima sebagai karyawan baru berdasarkan kriteria-kriteria yang ditentukan [6]. Penelitian Sistem Pendukung Keputusan pemilihan mitra freight forwarder untuk kegiatan ekspor menggunakan metode AHP dan SAW menjelaskan Konsep dasar metode SAW adalah mencari penjumlahan terbobot dari rating kinerja pada setiap alternatif pada semua atribut. Metode [7]. Penelitian Analisis Dan Perancangan Sistem Pendukung Keputusan Pemilihan Marketing Terbaik Dengan Menggunakan Fuzzy Multiple Atribut Decission Making, SAW (Simple Additive Weighting) menjelaskan mempermudah project manager dalam melakukan Langkah pengambilan keputusan, untuk pemilihan team marketing terbaik [8][9]. Penelitian Penerapan Sistem Pendukung Keputusan Penilaian Karyawan Terbaik Dengan Metode Simple Additive Weighting menguraikan Penilaian Karyawan terbaik dengan banyak kriteria (multikriteria) dan memerlukan waktu pemrosesan yang relatif cepat [10].

\section{Tinjauan Pustaka}

2.1. Ssitem Pendukung Keputusan (SPK)

SPK didefinisikan sebagai sebuah sistem yang mendukung kerja seorang manajer maupun sekelompok manajer dalam memecahkan masalah semi-terstruktur dengan cara memberikan informasi ataupun usulan menuju pada keputusan tertentu. Sistem pendukung keputusan adalah sistem berbasis komputer interaktif, yang membantu pengambil keputusan dengan menggunakan data dan model keputusan untuk memecahkan persoalan-persoalan yang tak terstruktur [11]. Komponen Sistem Pendukung Keputusan, meliputi database, yang mengandung data yang relevan untuk berbagai situasi dan diatur Database Management System (DBMS). Model Management, melibatkan model finansial, statistikal, management science, atau berbagai model kualitatif lainnya, sehingga dapat memberikan ke sistem suatu kemampuan analitis, dan manajemen software yang dibutuhkan [12]. Communication User, berkomunikasi dan memberikan perintah pada DSS melalui subsistem ini. Ini berarti menyediakan antarmuka. Knowledge Management Subsistem optional ini dapat mendukung subsistem lain atau bertindak atau bertindak sebagai komponen yang berdiri sendiri. SPK dirancang untuk pendekatan menyelesaikan masalah para pembuat keputusan dan kebutuhan-kebutuhan aplikasi, tetapi tidak menggantikan maupun membuat keputusan untuk pengguna [13].

2.2 Simple Additive Weighting (SAW)

Metode Simple Additive Weighting (SAW) sering juga dikenal istilah metode penjumlahan terbobot. Konsep dasar metode SAW adalah mencari penjumlahan terbobot dari rating kinerja pada setiap alternatif pada semua atribut [14]. Metode SAW membutuhkan proses normalisasi matriks keputusan (X) ke suatu skala yang dapat diperbandingkan dengan semua rating alternatif yang ada [15]. Metode SAW ini mengharuskan pembuat keputusan menentukan bobot bagi setiap atribut. Skor total untuk alternatif diperoleh dengan menjumlahkan seluruh hasil perkalian antara rating (yang dapat dibandingkan lintas atribut) dan bobot tiap atribut. Rating tiap atribut haruslah bebas dimensi dalam arti telah melewati proses normalisasi matriks sebelumnya.

\section{Metode Penelitian}

Langkah penelitian penerapan metode SPK - SAW sebagai berikut :

1. Analisa masalah

Dalam menentukan pilihan kain di Crown Textile \& Tailor, konsumen hanya melakukan secara subyektif dengan beberapa pertimbangan, yaitu dari segi harga dan warna. Namun di peroleh fakta bahwa ketika dijadikan pakaian atau baju, tidak sesuai dengan kriteria-kriteria yang diinginkan oleh konsumen dan banyak pakaian yang warnanya menjadi kusam atau luntur. Oleh karena itu dirumuskanlah permasalahan dalam penelitian ini yaitu bagaimana melakukan pemilihan kain dengan mempertimbangkan berbagai kriteria menggunakan metode SAW (Simple Additive Weighting).

2. Pengumpulan Data

Tahap ini dilakukan untuk mengumpulkan data-data yang dibutuhkan untuk penelitian seperti data primer 
dapat berupa opini subjek (orang) secara individual atau kelompok, hasil observasi terhadap suatu benda (fisik), kejadian atau kegiatan dan hasil pengujian. Data ini didapat dari metode wawancara, Data Sekunder, biasanya berbentuk dokumen, file, arsip atau catatan-catatan perusahaan. Data ini diperoleh melalui dokumentasi perusahaan dan literatur yang berhubungan dengan penelitian selama periode waktu tertentu.

3. Analisa Data

Crown Textile \& Tailor dalam pemilihan kain terbaik belum menggunakan sistem sama sekali. Pengelolaan data secara perkiraan mengakibatkan permasalahan yang sering muncul yaitu dalam proses pemilihan kain terbaik membutuhkan waktu dan tenaga yang banyak, juga hasil yang didapat kurang akurat karena bisa saja terjadi banyak kekeliruan disana. Untuk mengatasi permasalahan tersebut perlu dibuat adanya suatu program aplikasi Sistem Pendukung Keputusan yang dapat membantu mempermudah pemilihan kain terbaik dengan metode Simple Additive Weighting (SAW).

4. Penerapan Metode SAW

Pengolahan data dalam penelitian pada Crown Textile \& Tailor dilakukan dengan perhitungan menggunakan Metode Simple Additive Wieghting (SAW).

a. Menentukan Kirteria,

Kriteria dipakai dalam memilih suatu alternatif dalam memecahkan masalah yang kompleks atau tidak terstruktur dalam sub-sub masalah, lalu menyusunya menjadi suatu hirarki. Dalam menentukan kriteria juga diperlukan bobot kriteria berikut merupakan Keterangan Bobot untuk menentukan kriteria antara lain Sangat Tinggi (ST) : 5

Tinggi (T) : 4, Cukup (C) : 3, Rendah (R) : 2, Sangat Rendah (SR) : 1

b. Menentukan Rating Kecocokan

Menentukan rating kecocokan dari setiap alternatif pada setiap kriteria yang sudah ditentukan dan dibuat dalam bentuk tabel rating kecocokan.

c. Menentukan Matriks Keputusan

Pembentukan matriks keputusan (x) yang dibentuk dari tabel rating kecocokan dari setiap alternatif pada setiap kriteria

d. Perankingan Menghitung

Hasil akhir nilai preferensi (Vi) diperoleh dari penjumlahan dari perkalian elemen baris matriks ternormalisasi (R) dengan bobot preferensi (W).

5. Perancangan Sistem

Hasil analisis sistem yang telah diperoleh, kemudian peneliti menggambarkan perancangan sistem yang akan digunakan.

a) Perancangan UML

Data Tahap ini akan dibuat desain diagram UML dari sistem yang akan dikembangkan.

b) Perancangan Database

Tahap ini akan dibuat table table yang dibutuhkan untuk database yang akan digunakan pada aplikasi.

c) Perancangan Input Output

Tahap ini adalah melakukan perancangan input data yang akan berupa rancangan form juga rancangan output yang berupa hasil dari sistem.

6. Pengujian

Pengujian merupakan tahapan dimana aplikasi akan dijalankan, tahap ini diperlukan untuk mengetahui apakah sistem sesuai dengan tujuan yang ingin dicapai. Pada pengujian ini dilakukan pengujian metode dan pengujian sistem. Pengujian metode dilakukan dengan cara membuat proses perhitungan masing-masing metode yaitu metode SAW sehingga dapat terlihat jelas proses perhitungan dan persamaan hasil output berupa perankingan dari masing-masing metode tersebut. Dari pengujian masing-masing metode dapat diambil kesimpulan apakah penggabungan kedua metode ini lebih efektif digunakan atau tidak.

7. Implementasi

Implementasi sistem merupakan realisasi pembuatan sistem berdasarkan desain yang dibuat menerapkan perancangan sistem menggunakan PHP dan MySQL dibuat melalui web browser.

\section{Hasil dan Pembahasan}

Perusahaan textil mempunyai persyaratan utama dalam menghasilkan kain terbaik yaitu $40 \%$ dari jenis bahan, 30\% dari kualitas, $20 \%$ dari motif dan 10\% dari harga. Kriteria pemilihan kain yaitu Jenis Bahan (C1), Kualitas (C2), Motif (C3), Harga (C4). Deskripsi sistem pengembangan aplikasi pemilihan kain terbaik menggunakan metode SAW, yang bertujuan untuk membantu mendukung keputusan dalam menentukan perangkingan kain terbaik yang benar. Metode Simple Additive Weighting dalam prosesnya memerlukan kriteria-kriteria dan menentukan jenis atribut kriterianya yang akan dijadikan bahan perhitungan pada proses 
perankingan dan penilaian pemilihan kain terbaik.

Deskripsi sistem penngembangan aplikasi pemilihan kain terbaik menggunakan metode SAW, yang bertujuan untuk membantu mendukung keputusan dalam menentukan perangkingan kain terbaik yang benar. Metode Simple Additive Weighting dalam prosesnya memerlukan kriteria-kriteria dan menentukan jenis atribut kriterianya yang akan dijadikan bahan perhitungan pada proses perankingan dan penilaian pemilihan kain terbaik. Menentukan kriteria-kriteria yang dijadikan acuan dalam pendukung keputusan yaitu (C) jenis atribut kriteria sebagai berikut.

Tabel 1. Kriteria

\begin{tabular}{|l|l|l|}
\hline Kode Kriteria & Nama Kriteria & Jenis Atribut \\
\hline C1 & Jenis Bahan & Benefit \\
\hline C2 & Kualitas & Benefit \\
\hline C3 & Motif & Benefit \\
\hline C4 & Harga & Cost \\
\hline
\end{tabular}

Dari kriteria tersebut, maka dibuat suatu tingkat kepentingan kriteria berdasarkan nilai bobot yang telah ditentukan kedalam bilangan Fuzzy. Rating kecocokan setiap alternatif pada setiap kriteria.

Tabel 2. Bobot Tingkat Kepentingan

\begin{tabular}{|l|l|}
\hline Tingkat Kepentingan & Nilai \\
\hline Rendah (R) & 1 \\
\hline Sedang (C) & 2 \\
\hline Tinggi (T) & 3 \\
\hline
\end{tabular}

Kriteria dan ranting kecocokan setiap alternatif (Ai) pada setiap kriteria $(\mathrm{Cj})$ telah ditentukan, selanjutnya penjabaran bobot setiap kriteria $(\mathrm{Cj})$ ditentukan ke dalam bilangan Fuzzy.

a. Kriteria Jenis bahan kain

Tabel 3. Kriteria Jenis Bahan

\begin{tabular}{|l|l|l|}
\hline Jenis Bahan & Fuzzy & Nilai \\
\hline Kualitas rendah & Rendah & 1 \\
\hline Kualitas cukup & Cukup & 2 \\
\hline Kualitas tinggi & Tinggi & 3 \\
\hline
\end{tabular}

Kriteria jenis bahan kain merupakan persyaratan paling penting dan mempunyai bobot yang paling tinggi. Karena dengan jenis bahan kain yang bagus diharapkan bisa menjadikan kepuasan tersendiri oleh konsumen. Adapun kriteria dengan kualitas rendah menggunakan 30\% campuran serat kapan, untuk kualitas cukup menggunakan 75\% serat kapan dan kualitas tinggi menggunakan 100\% serat kapas.

b. Kualitas Kain

Tabel 4. Kriteria Kualitas

\begin{tabular}{|l|l|c|}
\hline Motif & Fuzzy & Nilai \\
\hline Kasar & Rendah & 1 \\
\hline Cukup lembut & Tinggi & 2 \\
\hline Sangat lembut & Sangat Tinggi & 3 \\
\hline
\end{tabular}

Kriteria kualitas kain merupakan salah satu persyaratan yang dibutuhkan dalam pengambilan keputusan. Adapun untuk jenis bahan sangat lembut adalah kain yang terasa dingin dikulit. Untuk jenis bahan yang cukup lembut adalah kain yang tidak kaku, dan kain yang memiliki jenis bahan kasar adalah kain yang bila dipakai terasa panas dan mudah kusut.

c. Kriteria Motif

Tabel 5. Kriteria Motif

\begin{tabular}{|l|l|l|}
\hline Bahan & Fuzzy & Nilai \\
\hline Polos & Rendah & 1 \\
\hline Simple & Cukup & 2 \\
\hline Glamor & Sangat Tinggi & 3 \\
\hline
\end{tabular}

Kriteria motif merupakan salah satu syarat yang dibutuhkan dalam pengambilan keputusan. Semakin disukai atau laku dipasaran gambarnya maka semakin tinggi nilai fuzzynya. Untuk kriteria polos merupakan kain yang 
tidak memiliki motif atau hanya satu warna saja, untuk kriteria simple adalah kain yang memiliki motif simple seperti motif garis, bulat sedangkan untuk kriteria glamor adalah jenis kain yang memiliki motif bunga, galaran, burung, truntum.

d. Kriteria Harga

Tabel 6. Kriteria Harga

\begin{tabular}{|c|c|c|}
\hline Jenis Bahan & Fuzzy & Nilai \\
\hline Murah & Rendah & 1 \\
\hline Cukup Mahal & Cukup & 2 \\
\hline Sangat Mahal & Tinggi & 3 \\
\hline
\end{tabular}

Kriteria harga berdasarkan harga per meternya. Semakin mahal harga kain tersebut maka nilai fuzzynya semakin tinggi. Kriteria murah meliputi harga 50 ribu atau dibawah 50 ribu, untuk kriteria cukup mahal dari harga 100-200, dan untuk kriteria sangat mahal lebih dari 200 ribu. Kriteria harga berdasarkan harga per meternya. Semakin mahal harga kain tersebut maka nilai fuzzynya semakin tinggi. Kriteria murah meliputi harga 50 ribu atau dibawah 50 ribu, untuk kriteria cukup mahal dari harga 100-200, dan untuk kriteria sangat mahal lebih dari 200 ribu.Diambil 4 jenis nama kain sebagai sample untuk pemilihan kain dengan metode Simple Additive Weighting (SAW), ditentukan :

1. Kain Katun Jepang $:$ Jenis Kain $=$ Cukup, kualitas $=$ Tinggi, motif $=$ Rendah, harga $=$ Cukup.

2. Kain Viscose Rayon: Jenis Kain $=$ Tinggi, kualitas $=$ Tinggi, motif $=$ Cukup, harga $=$ Tinggi .

3. Kain Katun Toyobo, Jenis Kain = Cukup, kualitas = Cukup, motif $=$ Cukup, harga=Tinggi.

4. Kain Lace Brukat, Jenis Kain = Tinggi, kualitas = Cukup, kualitas =Cukup, motif $=$ Rendah.

Langkah penyelesaian kasus diatas untuk pemilihan kain dengan metode Simple Additive Weighting (SAW) yaitu melalui langkah sebagai berikut :

Memberikan nilai setiap alternatif (Ai) pada setiap kriteria (Ci) yang sudah ditentukan. Supaya lebih jelas dimisalkan untuk kain Kain Katun Jepang $=$ A1, katun viscose Rayon $=$ A2, Kain Lace Brukat $=$ A3, Kain Katun Toyobo $=$ A4. Berdasarkan data kain diatas dapat menentukan rating kecocokan setiap alternatif pada setiap kriteria yang telah dikonversikan dengan bilangan fuzzy,

$$
x=\left[\begin{array}{llll}
2 & 3 & 1 & 2 \\
3 & 3 & 2 & 3 \\
2 & 2 & 2 & 3 \\
3 & 2 & 2 & 1
\end{array}\right]
$$

Memberikan nilai bobot (W) Pengambilan keputasan memberikan bobot preferensi (W) ini berdasarkan persyaratan utama yang telah ditentukan oleh perusahaan textil yaitu sebagai berikut:

1. $\mathrm{W} 1=$ Jenis Bahan $(40 \%)=40 / 100=0,4$

2. $\mathrm{W} 2=$ Kualitas $(30 \%)=30 / 100=0,3$

3. $\mathrm{W} 3=\operatorname{Motif}(20 \%)=20 / 100=0,2$

4. $\mathrm{W} 4=\operatorname{Harga}(10 \%)=10 / 100=0,1$

Menormalisasikan kedalam matriks R.

$$
R=\left[\begin{array}{cccc}
0.66 & 1 & 0.5 & 0.5 \\
1 & 1 & 1 & 0.33 \\
0.66 & 0.66 & 1 & 0.33 \\
1 & 0.66 & 1 & 1
\end{array}\right]
$$

Hasil perangkingan, Tabel

Tabel 7. Perangkingan

\begin{tabular}{|l|c|c|}
\hline \multicolumn{1}{|c|}{ Nama Alternatif } & Nilai & Rangking \\
\hline Kain Viscose Rayon (A1) & 0.933 & 1 \\
\hline Kain Lace Brukat (A2) & 0,9 & 2 \\
\hline Kain Katun Toyobo (A3) & 0.716 & 3 \\
\hline Kain Katun Jepang (A4) & 0.700 & 4 \\
\hline
\end{tabular}

Hasil pengolahan data kriteria dan alternatif menggunakan SAW diperoleh alternatif kain terbaik adalah A2 yaitu Katun Kombed dengan nilai 0.933.

1. Tampilan Halaman Menu Utama

Menu utama merupakan halaman awal yang akan kita lihat ketika login berhasil dilakukan. Halaman ini berisi header sebagai judul halaman, nama sistem, serta menu-menu yang dapat pilih, Gambar 1. 


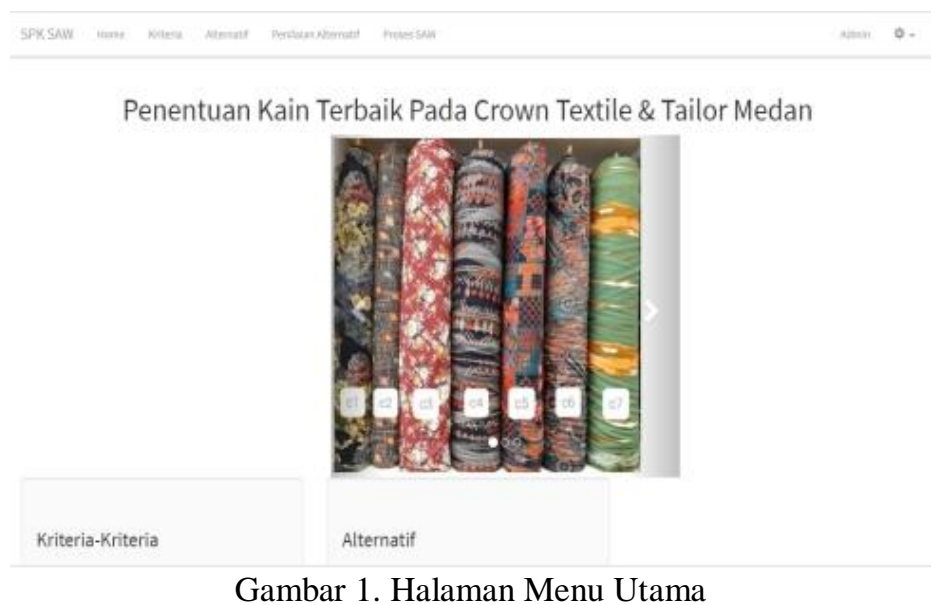

\section{Tampilan Halaman Menu Kriteria}

Pada tampilan menu kriteria digunakan untuk mengolah data kriteria. Pada halaman ini user bisa menambah, mengubah dan menghapus jenis gejala, Gambar 2.

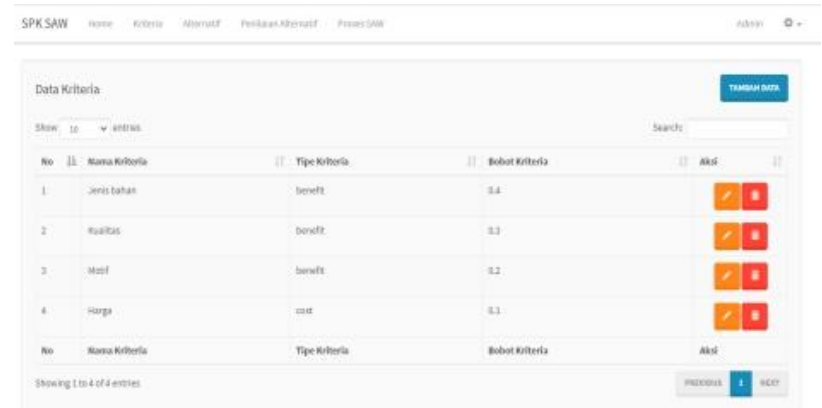

Gambar 2. Menu Kriteria

3. Menu Penilaian Alternatif

Pada tampilan menu ini merupakan tampilan yang digunakan untuk melakukan penilaian terhadap alternatif kain berdasarkan kriteria yang telah ditentukan. Tampilan halaman dirancang agar mudah untuk digunakan oleh user, Gambar 3.

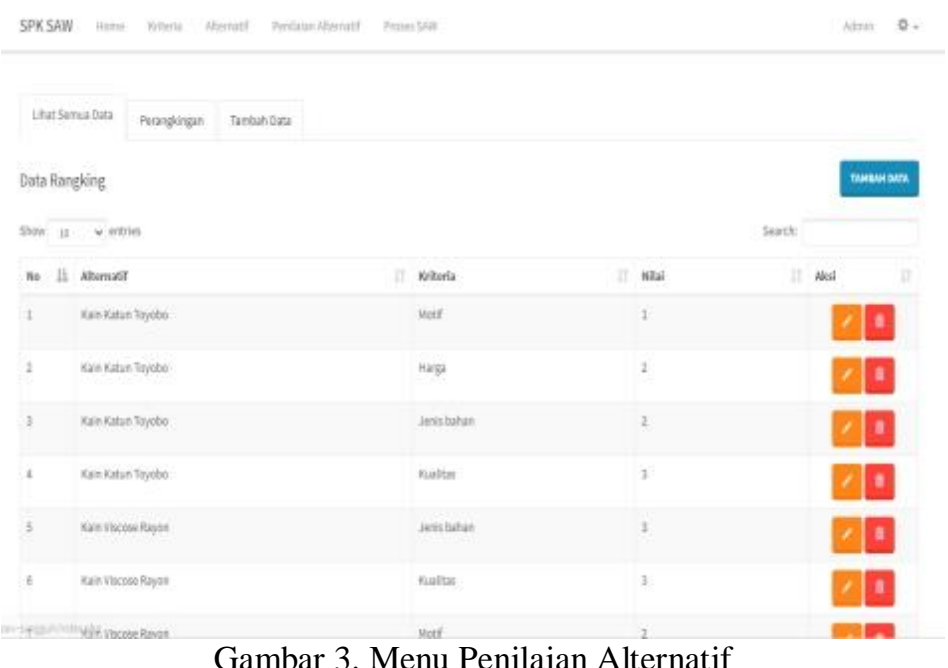

4. Tampilan Halaman Proses SAW

Pada halaman digunakan untuk menampilkan hasil proses metode saw yaitu hasil dari normalisasi dan hasil 
perangkingan alternatif kain, Gambar 4.

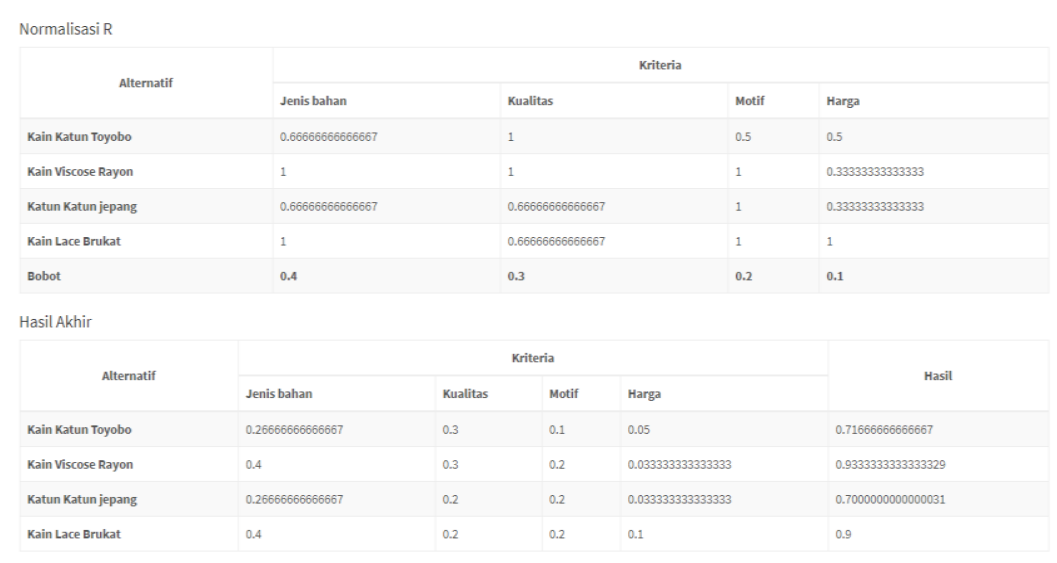

Gambar 4. Proses SAW

5. Halaman Perangkingan

Pada tampilan halaman Perangkingan merupakan tampilan hasil akhir dimana di halaman tersebut menunjukan hasil perhitungan alternatif kain, Gambar 5.

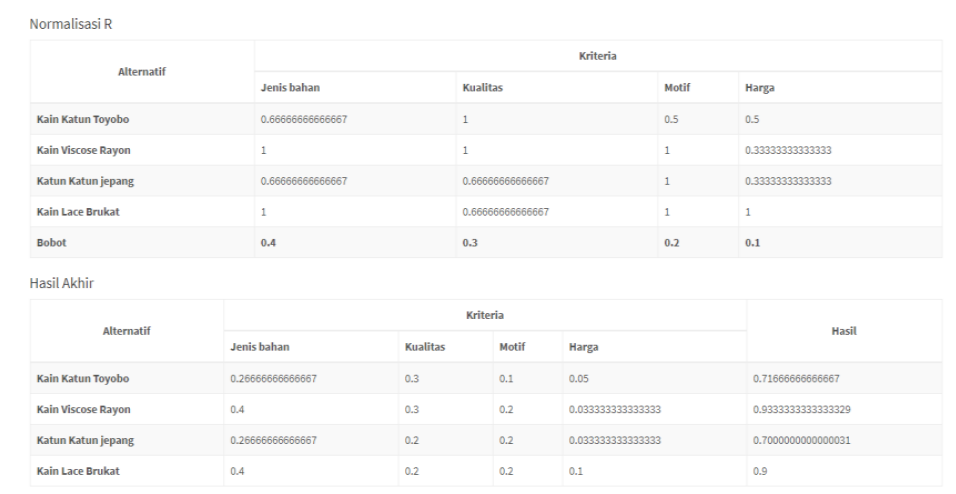

Gambar 5. Hasil Perangkingan

\section{Kesimpulan}

Kesimpulan dari perancangan, pembuatan, implementasi, dan evaluasi sebagai berikut :

1. Penerapan metode Simple Addictive Weighting pada Sistem Pendukung Keputusan Pemilihan Kain Terbaik Di Toko Crown Textile \& Tailor berhasil diterapkan dengan langkah-langkah metode SAW dari tahap awal sampe tahan akhir sehingga di dapatkan hasil 0.93 dengan nama kain viscose rayon.

2. Hasil keluaran dari aplikasi ini berupa alternatif kain dengan skor nilai tertinggi, sehingga dari alternatif kain tersebut bisa dijadikan acuan pertimbangan dalam memlilih kain.

3. Sistem yang dibuat dapat membantu Toko Crown Textile dalam penjualan dan membantu konsumen dalam memilih kain terhubung langsung ke database, sehingga data yang diproses disimpan didalam database.

\section{Daftar Pustaka}

[1] A. A, P. S. Ramadhan, and S. Yakub, "Sistem Pendukung Keputusan dalam Menenetukan Calon (Tailor) Penjahit di Ranhouse Medan dengan Menggunakan Metode AggregatedSum Product Assesment," J-SISKO TECH (Jurnal Teknol. Sist. Inf. dan Sist. Komput. TGD), vol. 3, no. 2, p. 12, 2020 .

[2] J. Sembiring and B. Sinaga, "Penerapan Metode Servqual Dalam Menentukan Tingkat Kepuasan Masyarakat Terhadap Pelayanan Pengurusan Surat Izin Usaha Mikro Dan Kecil Pada Kantor Camat Dolat Rayat Kabupaten Karo,” J. Nas. Komputasi dan Teknol. Inf., vol. 4, no. 2, pp. 165-170, 2021.

[3] FANDI AZIZ, "Sistem Penunjang Keputusan Penentuan Reward Bagi Mitra Terbaik Menggunakan Metode Simple Additive Weighting (SAW) (Studi Kasus : PT. Telkom Akses), J. Fasilkom, vol. 11, 
no. 2, pp. 91-96, 2021.

[4] H. Hariyanto and S. Khotimah, "Sistem Pendukung Keputusan Pemilihan Supplier Terbaik Telur Bermerk Menggunakan Metode SAW Studi Kasus : PT. GIANT PONDOK KOPI," J I M P - J. Inform. Merdeka Pasuruan, vol. 3, no. 2, pp. 47-53, 2018.

[5] F. Laila and A. Sindar, "Penentuan Supplier Bahan Baku Restaurant XO Suki Menggunakan Metode Weight Product," vol. 2, no. April, pp. 1-4, 2019.

[6] D. Mahdiana and N. Kusumawardhany, "Penerapan Metode Analytical Hierarchy Process dan Simple Additive Weighting untuk pemilihan Dosen Terbaik," Konf. Nas. Sist. Inf., vol. 8, no. 3, pp. 8-9, 2018.

[7] R. H. Sukarna, Y. Ansori, and T. Informatika, "Pendahuluan," vol. 10, no. 02, pp. 35-51, 2021.

[8] M. K. Wawan Manaheri, Fendi Hidayat, ST, “Analisis Dan Perancangan Sistem Pendukung Keputusan Pemilihan Marketing Terbaik Dengan Menggunakan Fuzzy Multiple Atribut Decission Making Dengan Metode Saw (Simple Additive Weighting)," vol. 10, no. 2, p. 3, 2018.

[9] S. Susmanto, Z. Zulfan, and M. Munawir, "Sistem Penerapan Fuzzy Multi Attribute Decision Making (MADM) Dalam Mendukung Keputusan Untuk Menentukan Lulusan Terbaik Pada Sekolah Tinggi Teknik Poliprofesi Medan,” J. Nas. Komputasi dan Teknol. Inf., vol. 1, no. 1, 2018.

[10] A. Zumarniansyah, R. Ardianto, Y. Alkhalifi, and Q. Nur Azizah, "Penerapan Sistem Pendukung Keputusan Penilaian Karyawan Terbaik Dengan Metode Simple Additive Weighting," J. Sist. Inf., vol. 10, no. 2, pp. 75-81, 2021.

[11] Nurul Putri Utami, Hasanul Fahmi, and Anita Sindar, "Spk Penentuan Pemberian Pinjaman Kepada Anggota Bumdes Dengan Metode Simple Additive Weighting," SINTECH (Science Inf. Technol. J., vol. 2, no. 2, pp. 124-130, 2019.

[12] S. Pendukung, K. Pemilihan, and P. Berprestasi, "JITaCS : Journal of Information Technology and Computer Science ADDITIVE WEIGHTING )," pp. 1-11, 2021.

[13] H. A. Prasetyo, "Sistem Pendukung Keputusan Menentukan Produsen Terbaik Dalam Pembuatan Kerudung Pada CV. Hazna Indonesia Menggunakan AHP (Analytical Hierarchy Process) dan WP (Weighted Product)," Semnasteknomedia Online, vol. 5, pp. 13-18, 2017.

[14] M. R. Ramadhan, M. K. Nizam, and ..., "Penerapan Metode SAW (Simple Additive Weighting) Dalam Pemilihan Siswa-Siswi Berprestasi Pada Sekolah SMK Swasta Mustafa," TIN Terap. Inform. ..., vol. 1, no. 9, pp. 459-471, 2021.

[15] W. A. Maulana, A. Nugroho, and T. Adriyanto, "Sistem Pendukung Keputusan Pemilihan Supplier Menggunakan Metode Simple Additive Weighting Di Toko Bangunan Ragil,” pp. 154-159, 2021. 